\title{
COMENTARIOS SOBRE LA REFORMA DE LA LEY GENERAL DE TURISMO DE COLOMBIA EFECTUADA POR LA LEY 1558 DE $2012^{1}$
}

Fernando CHARRIA GARCÍA ${ }^{2}$

SUMARIO: I. Introducción. II. Reforma de la Ley General de Turismo. III. Cierre. IV. Bibliografía.

\section{INTRODUCCIÓN}

Con la creación de la Ley 300 de 1996 asistimos a la generación de un estatuto sobre el derecho turístico en Colombia, que extrañamente ha sido objeto de escasos estudios jurídicos, que hacen preguntarse el porqué los estudios jurídicos lo han dejado tan aparte en Colombia. A pesar de tal señalamiento, este código tuvo una importante reforma legal en 2012, que requiere ser comentada en sus aspectos jurídicos.

El presente documento pretende evidenciar algunas dificultades y deficiencias de la reforma y de la normatividad jurídica del turismo en nuestro país, lo que frente a la ampliación de los procesos de turismo, tanto receptivo como doméstico y emisor que está mostrando Colombia, hace plausible pensar en la importancia de corregir algunas deficiencias y proponer indicaciones sobre algunos vacíos, a efectos de contribuir desde el campo del derecho al fortalecimiento de los desarrollos del turismo en nuestro país.

\section{REFORMA DE LA LEY GENERAL DE TURISMO}

La Ley 1558 de julio 10 de 2012 reformó a la Ley 300 de 1996, conocida como Ley General de Turismo, mediante la organización de seis títulos.

\footnotetext{
${ }^{1}$ El presente es un trabajo de reflexión, pues presenta resultados de investigación terminada sobre el derecho turístico en Colombia, desde una perspectiva analítica, interpretativa o crítica del autor. El proyecto del cual deriva es "Derecho turístico en Colombia". Originalmente el proyecto fue presentado en el grupo "Derecho, sociedad y cultura" de la Unidad Central del Valle del Cauca —UCEVA- (Colombia), dentro de la línea derecho de la cultura.

${ }^{2}$ Investigador principal, vinculado al programa de derecho de la Universidad Cooperativa de Colombia, sede Cali, como docente de tiempo completo, y pertenece al grupo de investigación de la Facultad de Derecho de esta Universidad.
} 
Esta revista forma parte del acervo de la Biblioteca Jurídica Virtual del Instituto de Investigaciones Jurídicas de la UNAM

La reforma introducida centra su interés en unas definiciones, en la creación de unos entes que deben contribuir con la organización del sector; en la generación de la contribución al turismo, con el fin de facilitar recursos para el sector turístico, y en algunas disposiciones finales que tocan una amplia variedad de aspectos.

El primer ámbito que toca es el relativo a los principios, que son conceptos fundamentales sobre los que se apoya un razonamiento. Así las cosas,

Los principios jurídicos son cláusulas de derecho condensado que no tienen la misma estructura de las reglas, aunque están dotadas de significado jurídico externo e interno: externo, porque hacen parte del ordenamiento jurídico, se han incorporado al derecho positivo; pero además, tienen un significado interno por sí mismos, un contenido jurídico relativamente preciso, aceptado convencionalmente por la comunidad jurídica. ${ }^{3}$

La introducción de doce principios en el estatuto sobre el derecho turístico debe estar en concordancia con los señalamientos que la Corte Constitucional ha efectuado al respecto, ${ }^{4}$ entendiendo que los principios son elementos esenciales para la discrecionalidad interpretativa, pues necesariamente los principios delimitan el sentido político de los textos normativos, pero que además, por ser conceptos deontológicos pertenecen al mundo del deber ser, y su eficacia interpretativa es indirecta, lo cual conlleva a que su aplicación sólo es real en la medida en que le ayude al intérprete para resolver el caso concreto y de una manera ponderada.

Otros autores señalan que: ${ }^{5}$

Los principios y valores, en su acepción técnico-jurídica (la única que aquí interesa), pueden ser reconducidos al género de los conceptos jurídicos indeterminados, de los que serían

\footnotetext{
${ }^{3}$ http://www.unilibre.edu.co/verbaiuris/images/stories/vo/1/dc3.pdf, citado en abril de 2015. Daza Duarte, Sandra Patricia y Quinche Pinzón, Rafael Humberto, Finalidad de los principios y valores constitucionales en el contexto del Estado social de derecho en Colombia.
}

${ }^{4}$ Corte Constitucional de Colombia. Sentencia T-406 de 1992 (M. P. Ciro Angarita Barón, junio 5 de 1992).

\footnotetext{
${ }^{5}$ Vaquer Caballería, Marcos, Estado y cultura: la función cultural de los poderes públicos en la Constitución española, Madrid, Centro de Estudios Ramón Areces-Universidad Carlos III de Madrid, 1998, p.103.
} 
Esta revista forma parte del acervo de la Biblioteca Jurídica Virtual del Instituto de Investigaciones Jurídicas de la UNAM

una especie. Dichos conceptos pueden ser definidos por la nota de que la medida concreta para su aplicación en un caso particular no nos la resuelve o determina con exactitud la propia Ley que los ha creado o los utiliza. ${ }^{6}$ Su rasgo esencial es, en definitiva, su abstracción o inconcreción.

\section{Sobre los principios en la reforma a la Ley General de Turismo}

Los principios enarbolados en la Ley 1558 de 2012 dada la importancia que ello conlleva, puesto que reformó los que tenía la Ley 300 de 1996, requieren de un acercamiento, para indagarlos y generar una adecuación.

Al mirar el principio de la Concertación, ${ }^{7}$ lo primero fue indagar en la jurisprudencia para encontrar la Sentencia C-862/12. ${ }^{8}$ En ella se entiende que la concertación implica "un proceso de diálogo social y político entre la sociedad civil, la institucionalidad y los demás actores que trabajan con y para la juventud". ${ }^{9}$ Es decir, que la primera referencia es de un proceso de interacción para algo, y no de mera comunicación o "socialización", como lo señala el principio en nuestra Ley en estudio. También buscamos en otras leyes;

\footnotetext{
${ }^{6}$ García de Enterría, Eduardo, La lucha contra las inmunidades del poder, 3a. ed., Madrid, Civitas, 1983, p. 34, en Vaquer Caballería, Marcos, op. cit., p. 103.

7Ley 1558 de 2012, julio 10 de 2012, Diario Oficial 48.487, artículo 30., numeral 1, concertación. En virtud del cual las decisiones y actividades del sector se socializarán en acuerdos para asumir responsabilidades, esfuerzos y recursos entre los diferentes agentes comprometidos, tanto del sector estatal como del sector privado nacional e internacional para el logro de los objetivos comunes que beneficien el turismo. Las comunidades se constituyen en parte y sujeto de consulta en procesos de toma de decisiones en circunstancias que así lo ameriten; para ello se acudirá al consentimiento previo libre e informado como instrumento jurídico ajustado al marco internacional de Naciones Unidas.
}

${ }^{8}$ Corte Constitucional de Colombia, sentencia C-862/12 (M. P. Alexei Julio Estrada, 25 de octubre de 2012).

${ }^{9}$ En la sentencia C-862/12 se pronuncia la Corte Constitucional en relación con el Proyecto de Ley Estatutaria núm. 169/11 Senado-núm. 014/11, cámara "Por medio de la cual se expide el Estatuto de la Ciudadanía Juvenily se dictan otras disposiciones", que define la concertación, razón por la cual se cita. 
Esta revista forma parte del acervo de la Biblioteca Jurídica Virtual del Instituto de Investigaciones Jurídicas de la UNAM

por ejemplo, la Ley 1361 de 2009, ${ }^{10}$ que en su artículo segundo define “integralidad y concertación" como el "Desarrollo de intervenciones integrales eficientes y coordinadas desde los diferentes niveles de la administración pública y en los componentes de la política". También aquí un proceso de participación, más que uno de mera comunicación o socialización. Lo curioso es que en la definición que estamos analizando se le confiere un contenido de valor diferente al que gramaticalmente se le otorga en el diccionario de la RAE, ${ }^{11}$ pues la norma en estudio le confiere al principio "acuerdo", una acepción de socialización, cuando en términos gramaticales la acepción es componer, ajustar, pactar, traer a identidad, acordar, cotejar, etcétera, y en términos legales y jurisprudenciales es un proceso que trae la idea de acordar, pactar, componer, que está en la misma línea del diccionario, y no en la que señala la Ley en comento.

Lo grave de lo anterior es que este concepto, como todos los principios o valores que son pautas deontológicas y axiológicas y por tanto susceptibles de ser reconducidos al género de los conceptos jurídicos indeterminados, ${ }^{12}$ tienden a constituirse en referentes de validez del ordenamiento, y en este caso del sector turístico en Colombia, sector que es muy amplio, y que requiere de sus atributos propios: generalidad, impersonalidad y abstracción, lo que nos obliga a decir que el lenguaje usado por la Ley debe ser frío, descriptivo, no didáctico, que sus términos o alocuciones deben ser castizos, evitando

${ }^{10}$ Ley 1361 de 2009, por medio del cual se crea la ley de protección integral a la familia. Diario Oficial 47.552 de 3 diciembre de 2009.

${ }^{11}$ (Del lat. concertāre). 1. tr. Componer, ordenar, arreglar las partes de una cosa, o varias cosas. 2. tr. Ajustar, tratar del precio de algo. 3. tr. Pactar, ajustar, tratar, acordar un negocio. U. t. c. prnl. 4. tr. Traer a identidad de fines o propósitos cosas diversas o intenciones diferentes. U. t. c. prnl. 5. tr. Acordar entre sí voces o instrumentos musicales. 6. tr. Cotejar, concordar una cosa con otra. 7. tr. Cineg. Dicho de los monteros: Ir con los sabuesos al monte divididos por diversas partes, visitar el monte y los lugares fragosos de él, y por la huella y pista, saber la caza que en él hay, el lugar donde está y la parte donde ha de ser corrida. 8. intr. Dicho de una cosa, concordar (corresponder con otra). 9. intr. Gram. Dicho de dos o más palabras variables, Concordar en los accidentes gramaticales. U. t. c. tr. 10. prnl. ant. Componerse y asearse. MORF. conjug. actual c. acertar.

${ }^{12}$ Vaquer Caballería, Marcos, op. cit., p. 103. 
Esta revista forma parte del acervo de la Biblioteca Jurídica Virtual del Instituto de Investigaciones Jurídicas de la UNAM

localismos, regionalismos, jergas y extranjerismos, además de que estén en armonía con la gramática del idioma.

Lo anterior es suficiente para afirmar que este principio definido como quedó en la Ley 1558 de 2012 contribuye a confundir y no realizar su función de validación del sistema.

Los principios de coordinación, descentralización, calidad y competitividad, contienen también graves errores. Así, en relación con la coordinación, ${ }^{13}$ la definición no debe intervenir en lo definido, entonces la coordinación no puede ser la forma en que las entidades deben actuar, pues nada define $o$ aclara.

La descentralización, ${ }^{14}$ tratada como está en el texto, conlleva a otro error, pues este principio no es de la responsabilidad de los diferentes niveles del ámbito público, como nos lo da a entender la norma en comento, sino como lo señala la $F A O{ }^{15}$ que la entiende como "El proceso de transferencia de una parte del poder y recursos del Estado nacional a las instancias del nivel regional o local". ${ }^{16}$

La calidad ${ }^{17}$ hace referencia al conjunto de propiedades inherentes a una cosa que permite valorarla con respecto a las restantes de su especie. Por eso, cuando la ponemos al lado de otro de los Ilamados principios en esta Ley 1558 de 2012, que es el principio

\footnotetext{
${ }^{13}$ Ley 1558 de 2012, 10 de julio de 2012, Diario Oficial 48.487, artículo 3o., numeral 2, coordinación. En virtud del cual las entidades públicas que integran el sector turismo actuarán en forma coordinada en el ejercicio de sus funciones.
}

${ }^{14}$ Ibidem, numeral 3, descentralización. En virtud del cual la actividad turística es responsabilidad de los diferentes niveles del Estado en sus áreas de competencia.

${ }^{15}$ FAO es la Organización de las Naciones Unidas para la Agricultura y la Alimentación.

${ }^{16}$ http://WWw.fao.org/docrep/006/ad724s/ad724s01.htm, citado en Junio de 2015.

\footnotetext{
${ }^{17}$ Ley 1558 de 2012, 10 de julio de 2012, Diario Oficial48.487, artículo 3o., numeral 10, calidad. En virtud del cual, es prioridad optimizar la calidad de los destinos y de los servicios turísticos en todas sus áreas, con el fin de aumentar la competitividad del destino y satisfacer la demanda nacional e internacional.
} 
Esta revista forma parte del acervo de la Biblioteca Jurídica Virtual del Instituto de Investigaciones Jurídicas de la UNAM

de competitividad, tenemos nuevamente desaciertos, por cuanto la manera en que la Ley define a la competitividad ${ }^{18}$ conlleva la idea de calidad; es decir, del mejoramiento, cuando en realidad competitividad es la capacidad de luchar en un determinado campo o en todos.

Los principios de planeación y libertad de empresa nos presentan equívocos, por cuanto en relación con planeación ${ }^{19}$ no define el contenido, sino que se acerca más a la idea de regla jurídica que como mandato imperativo se cumple o no se cumple, que a la idea de principio. En cuanto a la libertad de empresa, ${ }^{20}$ es un referente innecesario, pues ya existe su consagración en el artículo 333 superior, razón por la cual es vano, pues jurídicamente los valores y principios, al estar positivados en la carta fundamental, irrigan todo el ordenamiento.

El principio del desarrollo social, económico y cultural, $^{21}$ en realidad es un señalamiento que realiza la ley respecto del turismo como un derecho, cuestión que es

\footnotetext{
${ }^{18}$ Ibidem, numeral 11, competitividad. En virtud del cual, el desarrollo del turismo requiere propiciar las condiciones necesarias para el mejoramiento continuo de la industria turística, de forma que mediante el incremento de la demanda genere riqueza y fomente la inversión de capital nacional y extranjero.
}

${ }^{19}$ Ibidem, numeral 4, planeación. En virtud del cual las actividades turísticas serán desarrolladas de acuerdo con el plan sectorial de turismo, el cual formará parte del plan nacional de desarrollo.

${ }^{20}$ Ibidem, numeral 5, libertad de empresa. En virtud del cual, y de conformidad con lo establecido en el artículo 333 de la Constitución Política, el turismo es una industria de servicios de libre iniciativa privada, libre acceso y libre competencia, sujeta a los requisitos establecidos en la ley y en sus normas reglamentarias. Las autoridades de turismo en los niveles nacional y territorial preservarán el mercado libre, la competencia abierta y leal, así como la libertad de empresa dentro de un marco normativo de idoneidad, responsabilidad y relación equilibrada con los usuarios.

${ }^{21}$ Ibidem, numeral 8, desarrollo social, económico y cultural. El turismo conforme al artículo 52 de la Constitución Política, es un derecho social y económico de las personas dada su contribución al desarrollo integral en el aprovechamiento del tiempo libre y en la revalorización de la identidad cultural de las comunidades. 
Esta revista forma parte del acervo de la Biblioteca Jurídica Virtual del Instituto de Investigaciones Jurídicas de la UNAM

muy diferente a un principio; y en cuanto al principio de desarrollo sostenible, ${ }^{22}$ tiene una estructuración inadecuada, pues se está hablando de los principios rectores de la actividad turística; entonces, tener un principio que define que el turismo lo tiene en cuenta es un verdadero despropósito, peor si dice que el desarrollo sostenible se aplica en "tres ejes básicos: ambiente, sociedad y economía", si antes ha dicho que el turismo "se desarrolla en armonía con los recursos naturales y culturales", con lo cual solamente aborda dos de los tres ejes que considera básicos, dejando por fuera el eje económico.

El principio fomento ${ }^{23}$ es en realidad un verbo que conlleva una determinada acción cuyo significado gramatical es diferente al del lenguaje oficial del Diccionario de la lengua española de la Real Academia Española, ${ }^{24}$ pero que la Ley 1558 de 2012 cambia para otorgarle un contenido que se acerca al sentido enunciado en el principio de facilitación. ${ }^{25}$ El fomento aquí se plasma más como una regla de derecho que como un principio.

\footnotetext{
${ }^{22}$ Ibidem, numeral 9, Desarrollo sostenible. El turismo se desarrolla en armonía con los recursos naturales y culturales a fin de garantizar sus beneficios a las futuras generaciones. La determinación de la capacidad de carga constituye un elemento fundamental de la aplicación de este principio. El desarrollo sostenible se aplica en tres ejes básicos: ambiente, sociedad y economía.
}

${ }^{23}$ Ibidem, numeral 6, Fomento. En virtud del cual el Estado protegerá y otorgará prioridad al desarrollo integral de las actividades turísticas, recreacionales $y$, en general, todo lo relacionado con esta actividad en todo el territorio nacional.

${ }^{24}$ http://lema.rae.es/drae/?val=fomentar, 2001. Fomentar. (Del lat. fomentāre). 1. tr. Excitar, promover, impulsar o proteger algo. 2. tr. Atizar, dar pábulo a algo. 3. tr. Med. Aplicar a una parte enferma paños empapados en un líquido. 4. tr. p. us. Dar calor natural o templado que vivifique o preste vigor. La gallina fomenta los huevos.

${ }^{25}$ Ley 1558 de 2012, 10 de julio de 2012, Diario Oficial 48.487, artículo 3o., numeral 7, facilitación. En virtud del cual los distintos organismos relacionados directa o indirectamente con la actividad turística, simplificarán y allanarán los trámites y procesos que el consejo superior de turismo identifique como obstáculos para el desarrollo del turismo. 
Esta revista forma parte del acervo de la Biblioteca Jurídica Virtual del Instituto de Investigaciones Jurídicas de la UNAM

Finalmente, tenemos el principio de protección al consumidor, ${ }^{26}$ que tampoco define, pero señala su protección como obligación. Ahora, el estatuto del consumidor ${ }^{27}$ tiene una definición de "consumidor y usuario", norma que ostenta un carácter interpretativo, pues establece una definición; por lo tanto, al remitirnos a ella en desarrollo de la idea de que en el derecho todo concepto jurídico significa algo y no cualquier cosa, ${ }^{28}$ encontramos que establece una diferencia con lo propiamente gramatical, lo cual es jurídicamente posible, y termina convirtiendo en sinónimos consumidor y usuario. ${ }^{29}$

\section{Sobre las definiciones de la Ley 1558 de 2012}

La definición de excursionista para entenderla es necesario vincularla con la de turista, ya que están en íntima relación conceptual; en primer lugar, por cuanto el concepto de turista está ligado al hecho de un desplazamiento a un lugar diferente del de su residencia habitual; en segundo lugar, su impronta obliga un animus como motivo que impulsa su acto de desplazamiento, el cual está alejado de los compromisos laborales remunerados, y como último elemento, la estadía de por lo menos una noche en el lugar que visita. Con la anterior caracterización de turista efectuada en la Ley 300 de 1996, quedaban por fuera aquellas personas que a pesar de cumplir con dos de los tres elementos de la definición incumplían precisamente con el de la pernoctación de por lo menos un día; pero no por ello dejaban de ser turistas, y ésta es la razón por la que nos encontramos con la definición de excursionista. Por eso decíamos "hoy aparece

${ }^{26}$ Ibidem, numeral 13, protección al consumidor. Con miras al cabal desarrollo del turismo, el consumidor será objeto de protección específica por parte de las entidades públicas y privadas.

${ }^{27}$ Ley 1480 de 2011, 12 de octubre de 2011, Diario Oficial 48220, artículo 50.

\footnotetext{
${ }^{28}$ Sainz Moreno, Fernando, Conceptos jurídicos, interpretación y discrecionalidad administrativa, Madrid, 1976, p. 172.

${ }^{29}$ Ley 1480 de 2011, 12 de octubre de 2011, Diario Oficial 48220, artículo 5o., numeral 3, consumidor o usuario. Toda persona natural o jurídica que, como destinatario final, adquiera, disfrute o utilice un determinado producto, cualquiera que sea su naturaleza para la satisfacción de una necesidad propia, privada, familiar o doméstica y empresarial cuando no esté ligada intrínsecamente a su actividad económica. Se entenderá incluido en el concepto de consumidor el de usuario.
} 
Esta revista forma parte del acervo de la Biblioteca Jurídica Virtual del Instituto de Investigaciones Jurídicas de la UNAM

con más fuerza la idea de ligar al turismo con aquellas actividades realizadas por personas durante sus viajes y sus permanencias en lugares diferentes a los de su entorno habitual y por un tiempo, con cualquier tipo de finalidad que no esté relacionada con el ejercicio de su principal actividad remunerada en el lugar al cual se ha desplazado". ${ }^{30}$

La pregunta que cabe hacerse es si la normatividad turística vigente en Colombia requería de esta definición o no, o si simplemente era pertinente acogerse a algunas ya elaboradas en el campo de la doctrina haciendo uso de las fuentes del derecho, para evitar hierros o inutilidades, de tal suerte que se tenga en cuenta la importancia de una apropiada técnica legislativa.

La definición de capacidad de carga en turismo es algo sobre lo que se ha debatido ampliamente dada su importancia. Así, en Echamendi Lorente ${ }^{31}$ (2001) hace referencia a varios conceptos sobre capacidad de carga turística como el expresado por Mathieson y Wall (1986): "el número máximo de visitantes que puede usar un espacio sin una alteración inaceptable del medio físico y sin una disminución en la calidad de la experiencia conseguida por los visitantes", ${ }^{32}$ igualmente cita a Lime y Stankey con un concepto muy similar, al que le agregan el aspecto temporal para entender la capacidad de carga turística como “El tipo de uso (lo que hacen y cómo lo hacen) que se puede soportar en un periodo determinado sobre un área sin causar un excesivo daño tanto al medio físico como a la experiencia del visitante". ${ }^{33}$

${ }^{30}$ Charria García, Fernando, Derecho turístico en Colombia, Bogotá, Librería Ediciones del Profesional, 2009, p. 22.

${ }^{31}$ Echamendi Lorente, Pablo, "La capacidad de carga turística. Aspectos conceptuales y normas de aplicación", Anales de Geografía de la Universidad Complutense de Madrid, Madrid, 2001, p. 12

${ }^{32}$ Mathieson, Alister y Wall, Geoffrey, Turismo: repercusiones económicas, físicas y sociales, México, Trillas, 1986, en Echamendi Lorente, Pablo, "La capacidad de carga turística. Aspectos conceptuales y normas de aplicación", Anales de Geografía de la Universidad Complutense de Madrid, Madrid, 2001, p. 12.

${ }^{33}$ Lime, David y Stankey, George, “Carrying Capacity: Maintaining Outdoor Recreation Quality”, Proceedings Forest Recreation Symposium, Nueva York, College of Forestry, 1971, pp. 171-184. 
Esta revista forma parte del acervo de la Biblioteca Jurídica Virtual del Instituto de Investigaciones Jurídicas de la UNAM

Otras concepciones estructuran su concepto respecto de los impactos de la zona. Tal el caso de:

La capacidad de carga turística es la frecuentación turística que puede admitir continuamente el sistema socioeconómico regional sin que se modifiquen:

a) en el nivel de las estructuras económicas, sin tener necesidad de llamar continuamente a las estructuras no regionales o extranjeras;

b) en el nivel de las estructuras sociales, sin modificar radicalmente los equilibrios sociales anteriores;

c) en el nivel cultural, sin modificar profundamente los sistemas de valor imperantes;

d) en el nivel medioambiental, sin modificar las grandes características ecológicas iniciales. $^{34}$

La Organización Mundial de Turismo (OMT), al contemplar diversos puntos de vista señaló que

El concepto de capacidad de carga trata de establecer en términos mensurables el número de visitantes y el grado de desarrollo que es susceptible de alcanzarse sin que se produzcan situaciones perjudiciales para los recursos... Es la capacidad que se puede alcanzar sin daño físico para el medio natural y para el medio artificial, sin daño social/económico para la comunidad y la cultura locales o sin perjudicar el justo equilibrio entre desarrollo y conservación... En términos estadísticos, es el número de visitantes que pueden darse en un lugar a cualquier hora punta o durante un año sin que resulte en una pérdida de atracción o en daños para el medio ambiente... Se puede decir, en términos generales, que existe una saturación o un sobrepaso de la capacidad de carga cuando los movimientos de las personas, nacionales o internacionales, excede temporalmente el nivel aceptable por el medio ambiente físico y humano de la zona de acogida o destino. ${ }^{35}$

La idea de desarrollo sostenible generó una marcada influencia en las diferentes ciencias y desarrollos de las comunidades humanas, pues entiende que todo desarrollo

\footnotetext{
${ }^{34}$ Thurot, J. M., Capacité de Charge et production touristique, Ed. Aix-en-Province, Centre des Hautes Etudes touristiques, 1980, en Echamendi Lorente, Pablo, "La capacidad de carga turística. Aspectos conceptuales y normas de aplicación", Anales de Geografía de la Universidad Complutense de Madrid, Madrid, 2001, p. 13.
}

\footnotetext{
${ }^{35}$ Informe de la OMT, cit. por Cazes, 1992.
} 
social debe resolver las necesidades del presente sin comprometer las de las futuras generaciones. Existen dos grandes factores que influyen a la hora de estructurar la capacidad de carga turística. Uno son las características de los turistas, que mira a los niveles socioeconómicos, de uso, número de visitantes, estancia, duración, tipos de actividad turística y nivel de satisfacción turística, entre otros; y otro, son las características del área de destino y sus habitantes, que recoge aspectos como los rasgos naturales ambientales y sus procesos, la estructura social y sus formas de organización, la estructura económica y el desarrollo económico, el nivel de desarrollo turístico, etcétera.

El problema central radica en que el tipo de estudios y la diversidad de los mismos hacen que sea muy difícil extrapolarlos, pues sus instrumentos de medición son diferentes. En todo caso se nos presentan grandes dificultades al momento de establecer las capacidades de carga por varias razones, por la gran diferencia de las personas frente a la diversidad de necesidades turísticas que buscan; por la determinación del momento en que se valore o aprecie el cambio por el turismo y por saber cuándo dicho cambio deja de ser aceptable, pues todo uso turístico per se produce un cambio; entonces, reducir el indicador al número de personas visitantes es un verdadero reduccionismo lesivo.

La capacidad de carga turística implica juicios de valor, que obliga a pensar tres aspectos:

1. El contexto, que at inicio requiere de consultas previas de los distintos agentes implicados y de objetivos generales, lo cual obliga a pensar qué grado de actividad turística se pretende alcanzar y cuáles sus niveles de uso. La descripción del contexto, determinando los aspectos geográficos, político-jurídicos, el conocimiento del recurso turístico implicado; esto es, el terreno, la propiedad, los puntos de atracción, la infraestructura de alojamientos y la restauración, los parqueaderos, el transporte y las personas involucradas en la gestión turística del atractivo en referencia.

2. El estudio de las actividades turísticas incluye caracterización del perfil del turista, descripción de las actividades que realiza y posibles conflictos que puedan surgir, el análisis de los niveles de uso que se están dando, lo que ayudará a la cuantificación de los impactos del turismo. 
3. El carácter evaluativo de lo que se pretende gestionar turísticamente y, por ende, de la construcción de una estrategia de turismo, también requiere de estudio, por lo que hay que decidir qué variables y valores servirán como indicadores del desarrollo turístico. Esto necesita permanentes valoraciones y revisiones de los objetivos planteados, así como de las metas alcanzadas o por alcanzar, pues el turismo es una actividad cambiante en el tiempo.

La capacidad de carga turística lo que hace es generar una fuerte obligación para que estos estudios se hagan de manera local; además, obliga a un verdadero desarrollo reglamentado, para que no se convierta en un referente normativo inane.

En cuanto al referente de la calidad turística (artículo 5 de la Ley 1558 de 2012), creemos que es un importante avance tener normas técnicas sobre calidad expedidas por las diferentes unidades sectoriales de normalización del Ministerio de Comercio, Industria y Turismo, y que sean de obligatorio cumplimiento por parte de los prestadores de servicios turísticos, pero consideramos vital que dicho Ministerio no renuncie a su obligación de ejercer la supervisión y control sobre el cumplimiento normativo por parte de los prestadores de servicios turísticos.

\section{Sobre el Consejo Superior de Turismo}

La Ley 300 de 1996, artículo 80., decía: “El Consejo Superior de Turismo constituirá el máximo organismo consultivo del Gobierno Nacional en materia turística y estará integrado por...". Posteriormente, el Decreto 219 de 2000 en su artículo 19, derogó expresamente este artículo 80.; y ahora la Ley 1558 de 2012, en su artículo 40. vuelve a crear el Consejo Superior de Turismo con pequeñas variaciones.

El Consejo señalaba la presencia del jefe del Departamento Nacional de Planeación, pero la nueva Ley 1558 de 2012 lo retiró.

La norma anterior contempló la representación de los trabajadores provenientes de los sectores turísticos, escogidos por la central que demuestre tener mayor número de afiliados, ahora, el numeral 5 dice: "Los presidentes de los gremios nacionales del sector, uno por cada tipo de prestador turístico, el de mayor número de afiliados", con lo cual es necesario determinar cuáles son los gremios del sector, y que éstos idealmente se correspondan con los prestadores turísticos que en general son los de restaurantes (alimentos y bebidas), alojamientos, intermediación y el transporte. 
La anterior normativa estipuló la presencia de un decano de las facultades de Hotelería y Turismo reconocidas por el ICFES; ahora el artículo 80. numeral 6 nos dice: “Un representante de las facultades de Administración Turística o similares, de las instituciones de Educación Superior, que será elegido dentro de sus miembros por el Comité Nacional de Capacitación y Formación Turística".

Los delegados de la Corporación Conferencia Nacional de Gobernadores; de la Federación Nacional de Municipios, de las asociaciones territoriales de promoción turística, se excluyeron, al igual que el presidente de la Cámara Colombiana de Turismo, los tres representantes del sector privado, y un usuario de servicios turísticos delegado por la Liga Colombiana de Consumidores, también se excluyeron.

Las anteriores variaciones son huella de un interés que ha cambiado en la conformación del carácter de un Consejo Superior, para hacerlo más abierto a lo privado y cerrarlo hacia lo público, reduciendo el número de participantes.

La mayoría de sus miembros son ministros. Los que no son ministros son: el viceministro de Turismo cabeza del turismo en el Poder Ejecutivo; el director de la Unidad Administrativa Especial de Aeronáutica Civil, en razón al transporte aéreo; el director de la Unidad Especial de Migración de Colombia, por tratarse de la entidad que tiene que ver con la salida y el ingreso de turistas y excursionistas; el director de la Unidad Administrativa Especial de Parques Nacionales, por cuanto muchos de los lugares turísticos están en íntima relación con los recursos ambientales ubicados en nuestros parques nacionales naturales $y$, en tal sentido, es importante la presencia de un sector que puede hablar con propiedad de la capacidad de carga con posibilidades de extrapolación al sector turístico; el director general de la Policía Nacional, por razón de su labor, y el director general del Servicio Nacional de Aprendizaje (SENA), pues esta institución fue la primera que ofreció formación en el campo del turismo.

Extraña la ausencia de la Dirección Marítima y Portuaria (DIMAR), que es la autoridad colombiana encargada de ejecutar las políticas del gobierno en materia marítima en su jurisdicción, con lo cual todos los aspectos marítimos quedan sin un experto en este Consejo Superior de Turismo. Consideramos que su presencia es importante por la gran cantidad de atractivos turísticos costeros y marítimos, que se podrán emparentar con aspectos del patrimonio cultural subacuático, y que junto al Ministerio de la Cultura pueden gestionar acertadamente. 
La falta de señalamiento de las funciones del Consejo Superior nos parece extraña; posiblemente se han dejado para que el mismo Consejo Superior de Turismo pueda establecerlas, ${ }^{36}$ funciones que ya no tendrán carácter de ley, que es lo deseable, por técnica legislativa.

\section{Sobre el Consejo Consultivo de la Industria Turística}

La importante creación de un Consejo Consultivo de la Industria Turística refleja la necesidad por parte del Ministerio de Comercio, Industria y Turismo, de contar con un verdadero consejo asesor; por esta razón, se crea con un relativamente pequeño grupo de personas representantes y propone una integración público-privada, tal y como lo señala el artículo 80., numerales 5 y 6 que dicen:

5. Los presidentes de los gremios nacionales del sector, uno por cada tipo de prestador turístico, el de mayor número de afiliados.

6. Un representante de las facultades de Administración Turística o similares, de las instituciones de Educación Superior, que será elegido dentro de sus miembros por el comité nacional de capacitación y formación turística.

Lo anterior nos muestra la tendencia por parte del gobierno nacional a trabajar con los gremios. Esto no es malo, pero nuestra realidad nos indica que, por ejemplo, al intentar indagar sobre datos, indicadores y estadísticas del prestador turístico de alojamientos en la página web del Ministerio, no aparecen ni segmentados ni totalizados, frente a lo cual recurrimos al Registro Nacional de Turismo (RNT), que muestra el registro de 6,949 alojamientos turísticos; ${ }^{37}$ otro tanto nos sucedió con las agencias de viajes que señala la presencia de 4,665, que incluye 213 mayoristas, 1,326 agencias operadoras y 3,126 agencias de viajes; igualmente, con los prestadores de restaurantes, que nos muestra la existencia de 814 establecimientos de gastronomía y bares; y de la misma manera con el prestador turístico de transporte, con 192 registros. Estos datos

\footnotetext{
${ }^{36}$ Ley 1558 de 2012, julio 10 de 2012, Diario Oficia/48.487, artículo 7o., parágrafo 2.

${ }^{37}$ http://www.citur.gov.co/Estad\%C3\%ADsticas/Oferta/Prestadoresdeserviciostur\%C3\%ADsticosinscritosR NT.aspx, abril de 2015.
} 
contrastan con los de la Cotelco, ${ }^{38}$ que indican en su página web que en la actualidad cuentan con 800 empresas aliadas, y con el "informe de turismo de diciembre de 2014", que dice que para el tercer trimestre de 2014 se cuenta con 215,233 de área culminada con destino hotel, representando un incremento de $16.3 \%$ frente al mismo periodo de 2013 (185,099 metros cuadrados). Es decir, no hay datos claros al alcance de un usuario común, y no es posible establecer inferencias dada la diversidad de referentes.

Lo más grave para nuestros efectos, es que no es fácil determinar cuál es el gremio nacional de mayor número de afiliados, de los posibles que podrían haber por los campos de los prestadores turísticos (que serían cuatro), y dentro de cada campo la posibilidad de que hubiera varios gremios, parece desconocerse.

Lo tercero, es que al incorporar a "Un representante de las facultades de Administración Turística o similares, de las instituciones de Educación Superior", lo que se hace es poner en relación el ámbito de la "formación de cuadros" del sector turístico, entendido desde la perspectiva weberiana, en contacto con la realidad de la vida social y sus problemáticas, con lo cual se puede generar una interacción favorable para el sector educativo para realizar ajustes requeridos por la realidad social del turismo, y favorable para el sector turístico, porque la academia puede aportar aspectos que requieren ser tenidos en cuenta en las perspectivas públicas del sector turístico, lo cual se evidencia en el artículo 9 de la Ley 1558 de 2012, que habla de las funciones de dicho Consejo Consultivo de la Industria Turística.

Es así cuando vemos que de las pocas funciones atribuidas (solamente siete) tres de ellas hablan de las políticas, planes y programas, sea para su formulación y ejecución (función núm. 1), sea para el análisis del sector (función núm. 4), sea para el estudio de la implementación e impacto de sus políticas (función núm. 5).

De las restantes cuatro funciones, tres de ellas tienen que ver con la generación de acuerdos internacionales (función núm. 2), de acercamiento sectorial público-privado (función núm. 3), de estrategias de seguridad turística (función núm. 6). Por último, la función núm. 7, relativa a la designación de candidatos para la medalla al mérito turístico.

38

Asociación hotelera y turística de Colombia, página: http://www.cotelco.org, abril de 2015. 
Esta revista forma parte del acervo de la Biblioteca Jurídica Virtual del Instituto de Investigaciones Jurídicas de la UNAM

La generación de consejos consultivos de la industria turística en el ámbito territorial de los departamentos y de los municipios y distritos merece interés, pues el panorama de dichos entes crece enormemente, ya que Colombia tiene 1,123 municipios (de ellos sólo son cinco distritos: Cartagena, Barranquilla, Santa Marta, Buenaventura y Bogotá), y 32 departamentos, con lo cual podríamos tener potencialmente 1,155 consejos, lo que significa una infraestructura enorme de carácter asesor en cada ámbito territorial, con posibles dificultades de varios órdenes, que puedan hacer muy complejo el desarrollo de una política sectorial, dadas además las diferencias regionales, aunque tal estructura obedece a una mirada democrática participativa.

\section{Del Consejo Superior de la Microempresa y de la Pequeña y Mediana Empresa}

El Ministerio de Comercio Exterior y el de Desarrollo Económico se fusionaron mediante el Decreto Ley 210 de 2003, cuyo artículo 32 señaló:

Artículo 32. Comités sectoriales o técnicos. El Ministro de Comercio, Industria y Turismo podrá crear como organismos consultivos de las diferentes unidades programadoras del Ministerio, comités sectoriales o técnicos constituidos por funcionarios del Ministerio, por representantes de la agremiación o agremiaciones vinculadas al respectivo sector industrial, tecnológico, comercial, turístico, o de servicios, y por personas que posean especial conocimiento y práctica en el ramo correspondiente.

Estos comités asesorarán al Ministerio en el estudio de los planes indicativos, políticas y problemas específicos de los respectivos sectores.

El Gobierno Nacional reglamentará el procedimiento para la selección de los representantes de las asociaciones gremiales del sector privado en cada comité.

Este nuevo Ministerio creó mediante el Decreto-Ley 210 de 2003, artículo 50., al Consejo Superior de la Microempresa y de la Pequeña y Mediana Empresa, que mediante Acuerdo 002 del 19 de abril de 2013 se conformó por 19 representantes, pero no había representantes del sector turístico que también tiene Mipymes; por tal razón, la Ley 1558 de 2012, artículo 10, resolvió incluir "un representante de los gremios pertenecientes al sector turístico".

\section{Sobre el Consejo Nacional de Seguridad Turística}

El plan estratégico de seguridad turística, creado por el Ministerio de Desarrollo Económico, pretendió “incrementar la seguridad para los usuarios de servicios turísticos, mediante el establecimiento de estrategias, a partir de las cuales la policía de turismo, en 
Esta revista forma parte del acervo de la Biblioteca Jurídica Virtual del Instituto de Investigaciones Jurídicas de la UNAM

coordinación con el Ministerio y las entidades territoriales", ${ }^{39}$ contemplaba cinco estrategias, a saber: 1) control y prevención a empresas turísticas; 2) vigilancia de atractivos y actividades turísticas; 3) fortalecimiento de la información y orientación al turista en las regiones turísticas; 4) fortalecimiento de la policía de turismo, y 5) red de seguridad turística. Sobre la base de estas necesidades, la Ley 1558 de 2012 crea el Consejo Nacional de Seguridad Turística, y abre la posibilidad para crear los comités departamentales de seguridad turística, con los representantes de las mismas instituciones que integran el Consejo Nacional; es decir, 32 posibles comités más, para cumplir con las estrategias señaladas.

El Consejo Nacional Turístico, así como los comités departamentales de seguridad turística, se conforman por representantes de diez entidades, todas relacionadas con aspectos turísticos y con la seguridad desde diferentes ángulos, pues la seguridad es un elemento imprescindible para el buen desarrollo de este sector, que cada día crece con impactos en el PIB de la nación.

\section{Comités locales para la organización de playas}

La Ley 1558 de 2012 creó estos comités locales para la organización de playas, conformados por el Ministerio de Comercio, Industria y Turismo, la Dirección General Marítima (Dimar), y la respectiva autoridad distrital o municipal donde existan playas, con la función de establecer franjas en las zonas de playas destinadas al baño, al descanso, a la recreación, a las ventas de bienes de consumo por parte de los turistas y a la prestación de otros servicios relacionados con las actividades de aprovechamiento del tiempo libre que desarrollen los usuarios de las playas.

El Decreto 1766 de 2013 emanado del Ministerio de Comercio, Industria y Turismo, reglamentó el funcionamiento de dichos comités y señaló su integración por un representante del Ministerio, uno por la Dirección General Marítima, y uno por el alcalde municipal o distrital.

Las siguientes fueron las zonas de playa determinadas: 1. Zona de servicios turísticos; 2. Zona del sistema de enlace y articulación del espacio público; 3. Zona de transición; 4. Zona de reposo; 5. Zona activa; 6. Zona de bañistas; 7. Área de acceso para naves; 8.

39

http://www.mincit.gov.co/minturismo/publicaciones.php?id=16381, abril de 2015. 
Esta revista forma parte del acervo de la Biblioteca Jurídica Virtual del Instituto de Investigaciones Jurídicas de la UNAM

Zona para deportes náuticos, y 9. Zona para tránsito de embarcaciones. Lo que en estas zonas se implemente y su manera de hacerlo son objeto de ajustes y decisiones de estos comités.

\section{Turismo social}

La primera reforma es el artículo 13 de la Ley 1558 de 2012, que aumentó la del turismo social, que pasó de entender por personas con recursos económicos limitadas aquellas con cuatro salarios mínimos legales mensuales vigentes (smlmv) a dos; es decir, que se incluyó un importante núcleo poblacional que no tenía estas posibilidades turísticas.

La siguiente modificación surgió para adecuar la normativa a la fusión que sufrieran los ministerios de Desarrollo Económico y Comercio, por lo cual el artículo 33 de la Ley 300 de 1996 se transformó dándole un sentido de inclusión al turismo social en relación con la exigencia del artículo 52 superior, al indicar: “El Estado fomentará estas actividades e inspeccionará, vigilará y controlará las organizaciones deportivas y recreativas cuya estructura y propiedad deberán ser democráticas". Al desarrollar el concepto de estructura y propiedad democráticas se invocó acertadamente la inclusión, además de asumir la promoción de empresas del sector social que tengan iniciativa turística dirigida a la población con recursos económicos limitados, y la de promover en los sectores sociales donde el turismo pueda mejorar esa condición social. Por esto, las cajas de compensación familiar que desarrollen actividades en el campo del turismo social y la recreación, son parte de este ámbito.

La reforma al artículo 35 de la Ley 300 de 1996, que hablaba de las personas de la tercera edad, los pensionados y los minusválidos, amplió este sector, congruente con el énfasis social, para incorporar a los adultos mayores, pensionados, personas con discapacidad, jóvenes y estudiantes pertenecientes a estratos 1 y 2 , y en especial a los carnetizados niveles I y II del Sisben. ${ }^{40}$

\section{Contribución al turismo}

40

El Sistema de Identificación de Potenciales Beneficiarios de Programas Sociales (Sisben) es una herramienta que clasifica a los individuos de acuerdo con su estándar de vida y permite la selección técnica, objetiva, uniforme y equitativa de beneficiarios de los programas sociales que maneja el Estado, de acuerdo con su condición socioeconómica particular. 
La Ley 1558 de 2012 contempló una transformación de los aportantes de la contribución parafiscal para la promoción del turismo que había sido creada por la Ley 1101 de 2006 y reformada por la Ley 300 de 1996, pretendiendo incorporar tres nuevos aportantes, con lo cual se estaba creando un tributo sin las formalidades propias de un estatuto tributario; por esto, la Corte Constitucional declaró inexequible este artículo 16 de la Ley 1558 de 2012, por no cumplir con el artículo 154, inciso 4, de la Constitución Nacional "un trámite de carácter tributario sea iniciado en la Cámara de Representantes", condición que se omitió generando un vicio de forma, por lo cual la Corte Constitucional lo declaró inexequible. ${ }^{41}$

\section{Impuesto de timbre para inversión social con destino al turismo}

La Ley 1558 de 2012, artículo 17, otorga una prerrogativa al gobierno para que desarrolle programas de inversión social a través de proyectos de competitividad turística, para comunidades vulnerables por parte del Ministerio de Comercio, Industria y Turismo, para lo cual podrá destinar el recaudo realizado por el impuesto de timbre creado por la Ley 2 de 1976. Efectivamente, aquí la Ley no está creando un nuevo tributo, sino otorgando facultades para un uso determinado de algo ya creado, evitando caer en otra inexequibilidad.

Lo importante es que con esta norma se financiaron proyectos turísticos de sectores vulnerables. De hecho, la Ley 1558 de 2012 impactó los incentivos tributarios creados por la Ley 1101 de 2006 que pretendía generar un proceso de fortalecimiento y crecimiento del sector turístico, mediante esta herramienta de incentivos.

Así las cosas, se tenía que únicamente los prestadores de servicios turísticos debidamente inscritos en el Registro Nacional de Turismo podrán ser beneficiarios de los incentivos tributarios consagrados a su favor. La omisión de la actualización del Registro Nacional de Turismo, así como el incumplimiento en el pago de la contribución parafiscal, producirá la pérdida del incentivo tributario correspondiente al año fiscal en el cual se pretende la omisión o incumplimiento.

41

Corte Constitucional de Colombia, sentencia C-678 de 2013. 
Esta revista forma parte del acervo de la Biblioteca Jurídica Virtual del Instituto de Investigaciones Jurídicas de la UNAM

La reforma continuó con el referente del Registro Nacional de Turismo para fortalecerlo, pero haciendo referencia específica a tributos de carácter turístico de los órdenes nacionales o territoriales, eludiendo interpretaciones laxas tributarias.

\section{Del Fondo Nacional de Turismo}

La Ley 300 de 1996, en los artículos 42 y siguientes, contemplaba la creación de un Fondo de Promoción Turística, reformados por la Ley 1101 de 2006, respecto de los miembros del Comité de dicho Fondo; pero nuevamente la reforma de la Ley 1558 de 2012, artículo 20, cambia uno de los miembros por otro, y adiciona otro literal para permitir la presencia de ciertos invitados especiales. Los cambios fueron sustituir el literal e), que decía "Un alcalde designado por la Federación Colombiana de Municipios"; para que quedara así: “e) Dos alcaldes elegidos por solo un periodo de un año, que se elegirán de acuerdo a reglamentación que expida el Gobierno Nacional". Además, agregó el literal g), el cual quedó así:

A las reuniones del Comité Directivo del Fondo será invitado el Director (a) del Instituto Colombiano de Bienestar Familiar, cuando quiera que se discuta la destinación de recursos para la ejecución de políticas de prevención y campañas para la erradicación de turismo asociado a prácticas sexuales con menores de edad. El director de la aeronáutica civil o su delegado, podrán ser invitados cuando quiera que se discutan temas de infraestructura aeroportuaria. Los invitados tendrán derecho a voz pero no al voto en las reuniones del Comité.

\section{De los recursos del Fondo Nacional de Turismo}

Si antes se había constituido el Fondo de Promoción Turística, ahora la Ley 1558 de 2012, artículo 21, lo denominará Fondo Nacional de Turismo (FONTUR); mejorando sus recursos, al agregar los asignados en el presupuesto nacional para la infraestructura turística, la promoción y la competitividad turística, así como el recaudo del impuesto al turismo, con personería jurídica y patrimonio autónomo.

El Fondo se fortalece también por el artículo 22 de esta Ley, que hace referencia a los bienes con vocación turística incautados o con extinción de dominio, reglamentados por los decretos 2125 y 2503 de 2012, el primero de los cuales confirió facultades al Ministerio de Comercio, Industria y Turismo para que haga uso con fines de aprovechamiento turístico de los bienes de propiedad de la antigua Corporación Nacional de Turismo; y el segundo, relativos a los bienes incautados con vocación 
Esta revista forma parte del acervo de la Biblioteca Jurídica Virtual del Instituto de Investigaciones Jurídicas de la UNAM

turística, definiendo qué es esa vocación turística, y el procedimiento para que el Fondo Nacional del Turismo los pueda adquirir y realizar un aprovechamiento turístico.

\section{Del Banco de Proyectos}

La Ley 1101 de 2006, artículo 18, creó el Banco de Proyectos, ahora reformado por esta Ley, para indicar que los proyectos incluidos podrán tener una cofinanciación de hasta el $80 \%$ para municipios de 4, 5 y 6 categorías, y añadir en el parágrafo a otros municipios que quedan excluidos de los aportes de cofinanciación. Tales municipios son aquellos declarados como patrimonio histórico de la humanidad por la UNESCO, municipios de sexta categoría de San Agustín e Isnos en el departamento del Huila, Inzá (Tierradentro) en el departamento del Cauca, y Mompox en el departamento de Bolívar.

\section{Reformas varias}

Este acápite toca aspectos de variado orden, que mencionaremos a continuación.

\section{A. Fomento de los estudios turísticos}

La referencia a los estudios turísticos nos llama la atención, pues "reclama" para el Estado la unificación de criterios en el ámbito educativo respecto del sector turístico. Creemos que es importante que exista coherencia y unidad, ya que la necesidad de fortalecer este campo es inocultable, pues generará los "cuadros" que ocuparán los desarrollos que el sector requiere.

El hecho de que la Ley le señale al Ministerio del ramo que impulse convenios y acuerdos con el sector educativo para la formación universitaria del sector turístico, es destacable, al señalar la ruta de la inminente "profesionalización" del sector, pues es con procesos formativos de nivel profesional como podemos garantizar el desarrollo estructurado y sustentable del sector, desde una perspectiva humana.

\section{B. Guianza turística}

La Guianza turística en la reforma se reconoce "como profesional en el área de Guionaje o Guianza turística en cualquiera de sus modalidades, a la persona que esté inscrita en el Registro Nacional de Turismo, previa obtención de la correspondiente tarjeta profesional como guía de turismo", tarjeta que se entregará como mínimo a quien haya tenido una formación de tecnólogo.

También generó una ampliación, pues permite que otras personas se puedan desempeñar como guías de turismo, siempre que tengan título profesional en las áreas 
afines del conocimiento turístico determinadas por el ministerio del ramo, y haber aprobado el curso de homologación que el SENA diseñe para tal fin.

El bilingüismo es otra preocupación del sector que recoge el artículo 27 de la reforma, al imponer a la policía nacional la obligación de capacitar en un segundo idioma y en conocimientos turísticos a su personal destinado permanentemente en aeropuertos, puertos y terminales de transporte.

\section{Protección al turista}

Nos ha parecido de especial interés que se haya tenido en cuenta una protección al turista, por cuanto uno de los sujetos con mayor desprotección jurídica es precisamente el turista, con todo, esta reforma se nos antoja tibia, pues solamente en el parágrafo primero del artículo 25 es donde se propende por "soluciones ágiles y eficientes a los consumidores de servicios turísticos". Para ello, propone como etapa previa surtir un trámite de reclamación directa con el prestador de servicio y las empresas de transporte aéreo, lo cual no es muy claro, pues o bien se trata de los prestadores de servicios turísticos en plural, o se trata de los prestadores de servicios de empresas de transporte aéreo. En el primer caso, se hace innecesario nombrar a las empresas de transporte aéreo, pues de plano son prestadores de servicios turísticos; y en el segundo caso, si se trata solamente de las empresas de transporte aéreo, entonces se reduce en extremo la acción de "protección al turista", que es lo que se pretendía, toda vez que existen transportes terrestres y acuáticos.

El parágrafo dos del artículo 25 de esta reforma habla de las reclamaciones surgidas en la prestación del servicio de transporte aéreo, para señalar que serán resueltas exclusivamente por la entidad aeronáutica. Es una lástima haber desperdiciado la oportunidad para generar una verdadera acción de protección del turista que era lo deseable y no referirlo sólo a lo señalado.

\section{De los círculos metropolitanos turísticos}

Los círculos metropolitanos se reforman completamente para indicar que su creación debe estar acorde con la Ley de Ordenamiento Territorial, señalando que pueden presentar proyectos al Banco de Proyectos, y que los vehículos taxis que laboran en estos círculos metropolitanos no requerirán planillas para trasladarse a otros municipios del círculo. 
La mezcla "variopinta" en este artículo es triste, pues contraviene los principios básicos de técnica legislativa y unidad de materia, ya que acoge una gran diversidad de asuntos. Lo más importante en nuestra consideración es que el Ministerio de Comercio, Industria y Turismo, y el Ministerio de Transporte, están en mora de regular lo relacionado con el transporte turístico, separándolo del transporte especial y evidenciando los distintos medios terrestres, aéreos y acuáticos.

\section{E. Publicidad turística y estadística}

La reforma obliga a que en la publicidad de los prestadores de servicios turísticos se incluya el número del Registro Nacional de Turismo, y en los precios finales estén todos los aspectos que los afecten, como tasas, impuestos, etcétera. Frente a esto, y teniendo en cuenta la austeridad del gasto de las entidades públicas de acuerdo con la Ley 1474 de 2011, se logró que las entidades públicas que tienen patrimonios autónomos queden excluidas de esa obligación.

La imposición al DANE de estructurar estadísticas del sector hotelero con la debida precaución y secreto de dicha información, no deja de llamarnos la atención, en especial por el hecho de que se haya encargado solamente del sector hotelero, y no de los otros sectores propios del campo turístico, para unificar criterios y facilitar estudios.

\section{F. Registro Nacional de Turismo y administradores de propiedad horizontal}

La reforma delegó el Registro Nacional de Turismo a las cámaras de comercio, estableciendo su obligación como requisito previo de funcionamiento y su consecuente actualización, pues las cámaras de comercio son eficientes y efectivas en el manejo de datos y su actualización, aunque esa responsabilidad original sea del ministerio del ramo.

Los administradores de los inmuebles sometidos al régimen de propiedad horizontal en los cuales se preste el servicio de vivienda turística, cuando no estén autorizados por los reglamentos para ello, o no se encuentren inscritos en el Registro Nacional de Turismo, deben informarlo al Ministerio de Comercio, Industria y Turismo. Consideramos que lo mismo se debió exigir a los demás prestadores de servicios turísticos, por el principio de igualdad de trato ante la ley.

G. Garantías de servicios turísticos y coordinación de áreas naturales protegidas 
La ley reformadora exige por parte del Ministerio la constitución de garantías de cumplimiento debidas y legalmente constituidas en Colombia, de los servicios contratados por los turistas. Este avance se deja a la liberalidad del Ministerio, y lo mismo con el Ministerio del Transporte, pero sólo para el transporte aéreo, mostrando vacíos frente al transporte terrestre y el acuático.

La obligación expresa al Ministerio de Comercio, Industria y Turismo de sujetarse a los planes de manejo ambiental de las áreas naturales protegidas, emitidos por el Ministerio de Ambiente y Desarrollo Sostenible, es vital, y consecuente con ello no podemos olvidar que en 1972 la UNESCO contempló la Declaración Mundial de Patrimonio Natural y Cultural, por lo que la reforma contempló en cabeza del Ministerio de Comercio, Industria y Turismo la expedición de la política nacional que desarrolle la promoción del turismo arqueológico de San Agustín de Isnos en el departamento de Huila.

\section{CIERRE}

Los vacíos normativos se hacen evidentes en el ámbito de nuestra legislación turística. Uno de ellos tiene que ver con lo relativo al transporte turístico, que requiere de una mirada integral del transporte terrestre, acuático y aéreo, y que lo separe de la figura del transporte especial educativo.

El segundo vacío es relacionado con los prestadores turísticos de alojamientos, ya que es evidente la necesidad de reglamentar una serie de prestadores que aún no tienen cabida en nuestra actual legislación. Tal el caso de los albergues, los campamentos turísticos y, por último, el de las ciudadelas turísticas; cuya regulación se hizo recogiendo las experiencias de otros países del mundo.

Lo tercero es que hay una relación Estado-gremios, pero lo importante es que realmente se promueva la generación de gremios de los diferentes prestadores turísticos, para que exista una verdadera masa crítica y la relación Estado-gremios enunciada en la Ley sea una adecuación democrática.

Lo cuarto es la importancia entre el derecho, el turismo, las nuevas tecnologías y los impactos y transformaciones que esto está generando.

Lo último es que debe quedar muy claro que el Ministerio de Comercio, Industria y Turismo, por más que tenga un sano acercamiento gremial, con ello no puede sustituir ni delegar su función de intervención supervisora sobre los prestadores turísticos, puesto que es su obligación como órgano gubernamental del Estado. 


\section{BIBLIOGRAFÍA}

AURIOLES, A., Introducción al derecho turístico. Derecho privado del turismo, España, Tecnos, 2005.

Boullón, R. C., Planificación del espacio turístico, México, Trillas, 1985.

Comisión de las Comunidades EuRopeas, hacia un desarrollo sostenible. Programa comunitario de política y actuación en materia de medio ambiente y desarrollo sostenible, Bruselas 1992.

Charria García, F., Derecho turístico en Colombia, Bogotá, Librería Ediciones del Profesional Ltda., 2009.

Daza Duarte, S. P. y Quinche Pinzón, R. H., Finalidad de los principios y valores constitucionales en el contexto del Estado social de derecho en Colombia, diponible en $h t t p: / / w w w . u n i l i b r e . e d u . c o / v e r b a i u r i s / i m a g e s / s t o r i e s / v o / 1 / d c 3 . p d f$, consulta del 10 de abril del 2015.

ECHAMENDi LoRENTE, P., "La capacidad de carga turística. Aspectos conceptuales y normas de aplicación", Revista Anales de Geografía de la Universidad Complutense de Madrid, 2001.

Fernández Álvarez, J., Curso de derecho administrativo turístico, España, 1974.

FERNÁNDEZ RodRíGUeZ, C., Derecho administrativo del turismo, 3a. ed., Madrid, Marcial Pons Ediciones Jurídicas y Sociales, 2005.

GETZ, D., Capacity to Absorb Tourism: Concepts and Implications for Strategies

González Ramírez, A., Introducción al derecho, 5a. ed., Santa Fe de Bogotá, Librería del Profesional, 1995.

MATHIESON, A. y WALL, G., Turismo: repercusiones económicas, físicas y sociales, México, Trillas, 1986.

Monroy CABRA, M. G., Introducción al derecho, 14a. ed., Bogotá, Temis, 2003.

Nieto ARTETA, L. E., Interpretación de las normas jurídicas, Buenos Aires, Ed. Jurídica Argentina, 1944.

“Planning", Annals for Tourism Research, vol. 10, 1983.

ThUROT, J. M., Capacité de Charge et production touristique, CHET, Aix-en-Province, 1980. 
Esta revista forma parte del acervo de la Biblioteca Jurídica Virtual del Instituto de Investigaciones Jurídicas de la UNAM

VAQUer CABAllería, M., Estado y cultura: la función cultural de los poderes públicos en la Constitución española, España, Centro de Estudios Ramón Areces-Universidad Carlos III de Madrid, 1998.

Vera Rebollo, J. E. et al., Análisis territorial del turismo, Barcelona, Ariel, 1997.

WTO, National and Regional Tourism Planning. Methodologies and Case Studies, Londres, Routledge, 1994. 